\title{
Ultrastructural Analysis and ABR Alterations in the Cochlear Hair-cells Following Aminoglycosides Administration in Guinea Pig
}

\author{
Mohammed A Akeel* \\ Department of Anatomy, Faculty of Medicine, Jazan University, Jazan, Kingdom of Saudi Arabia
}

Submission: April 18, 2018; Published: May 08, 2018

*Corresponding author: Mohammed A Akeel, Faculty of Medicine, Jazan University, P.O.Box 114, Jazan, Kingdom of Saudi Arabia.

Tel: +966561120210; Email: m.akeel@jazanu.edu.sa

Abstract

Aims: Aminoglycosides (AG) antibiotics were the first ototoxic agents to highlight the problem of drug-induced hearing and vestibular loss, since their introduction in the 1940. The aim of the present work was to characterize ultrastructural alterations of the sensory hair-cell following different aminoglycosides administration, intratympanic VS intraperitoneal and to correlate them with auditory brainstem responses (ABR).

Methods: A total of 48 adult guinea pigs were divided into 8 groups; six animals in each group. The first four groups received saline (control), streptomycin, gentamycin, or netilmicin; respectively, via the peritoneal route. The next four groups received similar treatment via transtympanic route. The treatment was administered for seven consecutive days. On day 10, ABR was utilized for hearing evaluation and scanning electron microscopy (SEM) examination of the sensory organs was used for morphological study.

Results: Streptomycin produced the most severe morphological changes and a higher elevation of ABR thresholds, followed, in order, by gentamycin and netilmicin. Netilmicin ototoxicity observed in both systemic and transtympanic routes was low because of lesser penetration into the inner ear or/ and lower intrinsic toxicity.

Conclusion: Streptomycin cochleotoxicity lesion involves destruction of the sensory hair cells of the cochlear epithelium which was quantified functionally and ultrastructurally. Streptomycin was the most cochleotoxic among the AG administrated, followed by gentamycin and netilmicin. Moreover, we demonstrated the presence of surface scavenger microphages in close association with auditory hair cells in the normal physiological conditions. Such cells may form part of the resident immune surveillance of organ of Corti.

Keywords: ABR: Auditory Brainstem Responses; Guinea pig; (AGs): Aminoglycosides; SEM: Scanning Electron Microscopy

\section{Introduction}

The sensory hair cells within the cochlea of the mammalian inner ear convert sounds into receptor potentials when their projecting stereocilia are deflected. The organ of Corti of the cochlea contains two types of hair cells (HC): inner and outer hair cells (IHCs and OHCs), which differ in function. It has been appreciated for over two decades that although IHCs act as the primary receptor cells for the auditory system, the OHCs act as motor cells. OHCs respond to variation in potential, and change length at rates unequalled by other motile cells. The forces generated by outer hair cells are capable of altering the delicate mechanics of the cochlear partition, increasing hearing sensitivity and frequency selectivity [1].

The mammalian organ of Corti contains at least seven different supporting cell (SC) types: Deiters' cells, pillar cells, Hensens' cells, inner phalangeal cells, inner border cells, Claudius' cells, and Boettcher cells. All of these supporting cell types are required for normal hearing function [2]. Hair cell and supporting cell developments are completed during early embryonic formation of the mammalian cochlea. In mammalian injury, no hair cell replacement is observed, as opposed to birds, where regenerative mechanisms produce new sensory cells and restore the auditory function. Notably, in neonates, certain cell populations of the organ of Corti are multipotent; they can proliferate and generate otic spheres, as well as differentiate and express hair cell markers, after being mechanically isolated and grown in culture in vitro [3]. In spite of the introduction of new classes of antibiotics, the aminoglycosides: streptomycin, gentamycin and netilmicin still remain the primary agents of choice in treating serious gram-negative infections [4]. It is well known that the use of aminoglycosides antibiotics carries a risk of cochleotoxicity. Yet they are still used because of their effectiveness and low cost $[5,6]$. The potential for cochleotoxicity of aminoglycosides has been investigated by many clinical studies [7-9]. Three primary factors identified with increased cochleotoxic risk are the total daily dose (in illigrams/per kilogram), the course length, and repeated courses of therapy $[9,10]$. The mechanisms underlying their selective toxicity to 
the inner ear continue to be unraveled despite more than 70 years of investigation [11]. Moreover, inflammation caused by severe bacterial infections also increase cochlear uptake of aminoglycosides and subsequent ototoxicity [12]. Preclinical models with systemic inflammation, induced by low doses of bacterial lipopolysaccharides displayed increased cochlear uptake of aminoglycosides, and enhanced levels of cochleotoxicity without altered serum drug levels [13]. The effects of aminoglycosides on neurosensory hair cells of the cochlea are well documented [14-17]. Yet, few comparative analysis of systematic vs. transtympanic administration of various aminoglycosides and their induced cochleo-toxicity was reported. This was mainly achieved through immunohistochemistry, light microscopy examinations and other similar modalities, except the ultrastructural level. The following study, therefore, aims at comprehensive morphological characterization of the cochlear hair cells following aminoglycosides using scanning electron microscopic (SEM) examination and combining it with auditory brain stem response (ABR) investigation.

\section{Materials and Methods}

\section{Animals and Study Groups}

A total of 48 guinea pigs, each weighing 250-300 grams, were obtained from animal house of the research centre. All the animals were kept under optimum conditions. Animal care was in compliance with research regulation and resolution. The experimental protocol was approved by Ethic Committee of Animal Research. Guinea pigs were divided into 8 groups; six in each group. In the first four groups drug administration was performed via the peritoneal route (systemic) for seven consecutive days as follow: $2 \mathrm{ml}$ of saline solution vehicle only in group I (control), 125mg/kg streptomycin in group II, 50mg/ $\mathrm{kg}$ gentamycin in group III and $37.5 \mathrm{mg} / \mathrm{kg}$ netilmicin, (1-N-ethyl derivative of sisomicin) in group IV. The doses were 10-20 times higher than the recommended human dosage. For the next four animal groups the aminoglycosides were administrated at $0.25 \mathrm{ml} / \mathrm{kg}$ in a $4 \%$ saline $40 \mathrm{mg} / \mathrm{ml}$ via trans-tympanic route for seven consecutive days through the right external meatus, as follow: saline for group V, streptomycin for group VI, gentamycin for group VII and netilmicin for group VIII. The guinea pigs were anesthetized with intraperitoneal injection of diazepam $3 \mathrm{mg} / \mathrm{kg}$ and the animals were kept in prone position to insure the drugs reached to the target structures.

\section{Auditory Brain Stem Response (ABR)}

ABR testing was performed under general anesthesia. Animals were placed on a preheated non-electric heating pad $\left(37^{\circ} \mathrm{C}\right)$ and needle electrodes were placed on the vertex and behind each pinna. ABRs were evoked with clicks and/or 5 $\mathrm{ms}$ tone pips ( $0.5 \mathrm{~ms}$ rise/fall, at $30 / \mathrm{sec}$ ) at frequencies of 0.5 , 1.2., 4, 8, 16 and $32 \mathrm{kHz}$. The signal was amplified, filtered, and averaged using the Intelligent Hearing System Smart-EP (Miami FL, USA). Thresholds were defined as the lowest level at which a reproducible response could be obtained. ABRs were performed prior to trans-tympanic (TT) injection or intra-peritoneal (IP) injections.

The sound level was raised in 20- and/or 5-dB steps. At each level, 1000 responses were averaged. Both ears were measured. Animals with abnormal baseline ABR were excluded from the experiment. Then, ABR evaluations were performed on day 10 , i.e. 72 hours after the last aminoglycosides doses were given. All procedures and animal handling described in this protocol were similar to those adopted by Murillo-Cuesta et al [18]. ABR results were compared using a three-way ANOVA. The effects of the frequency $(0.5,1,2,4,8,16$ and $32 \mathrm{kHz})$, on the side treated (right vs. left) and the different aminoglycosides intraperitoneal (IP) vs. transtympanic (TT) were measured and compared for significance at $\mathrm{p}>0.05$.

\section{Tissue Preparations For Scanning Electron Microscope}

Seventy two hours after giving the last dose of each aminoglycoside, the animal were anesthetized with intraperitoneal injection of diazepam $3 \mathrm{mg} / \mathrm{kg}$, perfused with sterile phosphate buffer solution PBS (with $\mathrm{Ca} 2+$ and $\mathrm{Mg} 2+$ ) and hereafter PBS++. Then the tissues were fixed by perfusion for 10 minutes in $1 \%$ glutraldehyde, $2 \%$ paraformaldehyde in phosphate-buffer at room temperature ( $\mathrm{pH}$ 7.4). The temporal bone was excised and the cochlea carefully removed through micro-dissection and fixed again in $1 \%$ glutraldehyde, $2 \%$ paraformaldehyde in phosphate-buffer at room temperature $\mathrm{pH}$ 7.4) for 60 minutes. Decalcification in EDAT was not performed. The cochlea was then washed twice in buffered sucrose for 5 min each (0.1 M phosphate buffer, $5 \%$ sucrose solution). Post fixation was performed at $4^{\circ} \mathrm{C}$ for $60 \mathrm{~min}$ in phosphatebuffered $2 \%$ osmium. The tissues were dehydrated in a graded series of ethanol $(40,50,70,80,90$, and twice in $100 \%)$, then ethanol- acetone (1:1) absolute solution for further 30 minutes, absolute acetone $100 \%$ for additional 30 minutes 3 times 10 minutes each. The tissues were critically point dried in $\mathrm{CO}_{2}$ drying apparatus CPD 030 and mounted on stubs, coated with gold sputter coater SCD005 and examined with Philips Scanning Electron Microscopy XL3 at 30kv.

\section{Semi-Quantitative Evaluation}

Damage of the stereocilia of outer hair cells (OHCs) observed by scanning electron microscopy (SEM) was classified into: normal, grade 1 (10-50\% loss of stereocilia), grade 2 (less than $50 \%$ remaining stereocilia), or grade 3 (missing stereocilia). Thirty OHCs of each row in the middle part of each turn of the cochlea were counted (a total of 90 cells per turn). Scores out of 10 were given and presented in a graph for comparison. The results were compared for statistical significance at $p>0.05$.

\section{Results}

\section{Auditory brainstem response (ABR)}

Thresholds of auditory brainstem response (ABR) were measured in decibels of sound pressure level (dBSPL) in the 
control and the aminoglycosides- treated guinea pigs. The effects of different frequencies $(0.5,1,2,4,8,16$ and $32 \mathrm{kHz})$ are presented in graph 1. It shows that the ABR threshold for the control groups, which received intraperitoneal (IP) or transtympanic (TT) injections of normal saline, was $45 \mathrm{~dB}$. Guinea pigs treated with streptomycin showed higher ABR thresholds, particularly at stimuli of $2,8,16$, and $32 \mathrm{kHz}$, which reached up to $85 \mathrm{~dB}$. The effect of the streptomycin compared to control group was statistically significant at $p>0.05$. Less hearing impairment effect was produced by gentamycin and netilmicin, as manifested by its lower ABR thresholds, except those of the control. The effect of transtympanic aminoglycosides administration in all groups showed no statistically difference than that of intraperitoneal route, although it is at higher figures. It could be summarized that streptomycin caused more hearing impairment than gentamicin and netilmicin, as manifested by a higher elevation of ABR thresholds in group (Graph 1). All thresholds of hearing loss regarding each frequency in both the control and the experimental groups are shown in graph 1 .

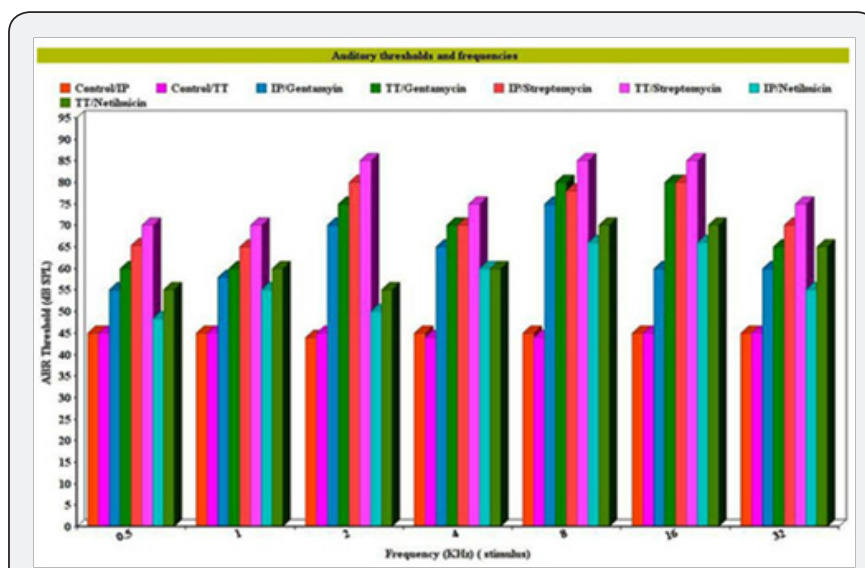

Graph 1: Representation of an $A B R$ testing. $A B R$ thresholds (decibels of sound pressure level, dBSPL) were measured in guinea pig with normal ABR (Black, Blue and Green).

\section{SEM of organ of Corti of the Control groups}

The cochlea is spiral shaped with two-and half turns around the modulus (Figure 1). The cochlear duct spirals inside the cochlea and contains the auditory sensory organ; organ of Corti (Figures 1 \& 2). The cochlear duct is a wedge-shaped duct surrounded on two sides by perilymph but separated from it by two membranes. The roof of the cochlear duct is the vestibular membrane whereas the floor is the basilar membrane. The perilymph compartments are the scala vestibuli above and the scala tympani below the cochlear duct. The organ of Corti is located on the basilar membrane of the cochlear duct (Figures 2-7). It consists of sensory hair cells and supporting cells. The sensory hair cells have numerous stereocilia projecting from their free end and are in close contact with gelatinous and fibrous structure called the tectorial membrane (Figures $3 \& 6$ ). The sensory hair cells are formed of outer hair cells (OHCs) and inner hair cells (IHCs) (Figures 2,7,8). OHCs are formed of three rows carrying apical stereocilia in stair-case arrangement forming the characteristic V-shaped pattern ciliary bundles (Figure 9). The cilia within a single row are of the same height, whereas stereocilia of different rows are graded in height, the outermost row being the tallest (Figures $9 \& 10$ ). The V-shaped patterns have an acute in angle in the outer row and more obtuse in the inner row. The stereocilia of the IHCs are arranged in a flattened U-shaped pattern with a wider angle (Figures 11 \& 12) and the ciliary bundles are free standing. Filamentous structures, forming cross-links between stereocilia of the same row IHCs (side-toside links) have been seen on hair cells (Figure 12). The sensory hair cells are housed in a reticular membrane formed by the apical plates of supporting cells: phalangeal cells of Deiters' and inner and outer pillar cells. Among the supporting-cell types, the inner pillar cells normally have rectangular apical surfaces and form a single row between the IHCs and OHCs. Moreover three rows of Deiters' cells were seen (Figures 3-7). Linkage system of stereocilia includes both transverse linkage of the same row of OHCs as well as oblique linkage between the three rows (Figure 13). Side-to-side links of OHCs were numerous than that seen in IHCs (Figures 13 \&14). Moreover the stereocilia of the OHCs are in close contact with the tectorial membrane (TM) (Figure 15), in contrary the stereocilia of the IHCs which are not reaching the tectorial membrane (Figure 16). The length's variation of the stereocilia in the three rows with marked tapering of its bases and rounding of its apices could be seen (Figure 17). While the stereocilia of the IHCs are of the same height (Figure 18 ) and arranged in a flattened U shaped pattern, occasionally additional smaller and shorter inner row was seen (Figure 19). Characteristic large microphages (Kolmer-like cells) similar to epiplexus of the ependymal surface cells could be seen close to the OHCs (Figure 20). They display diverse morphological forms and bear a variable number of cellular processes (foot process). These cells may play a role in the initiation and/or maintenance of the cellular immune response. The spiral ganglia that contain bipolar cell bodies of the first order neuron were visible (Figure 21). They are laying information from the organ of Corti to the brain.

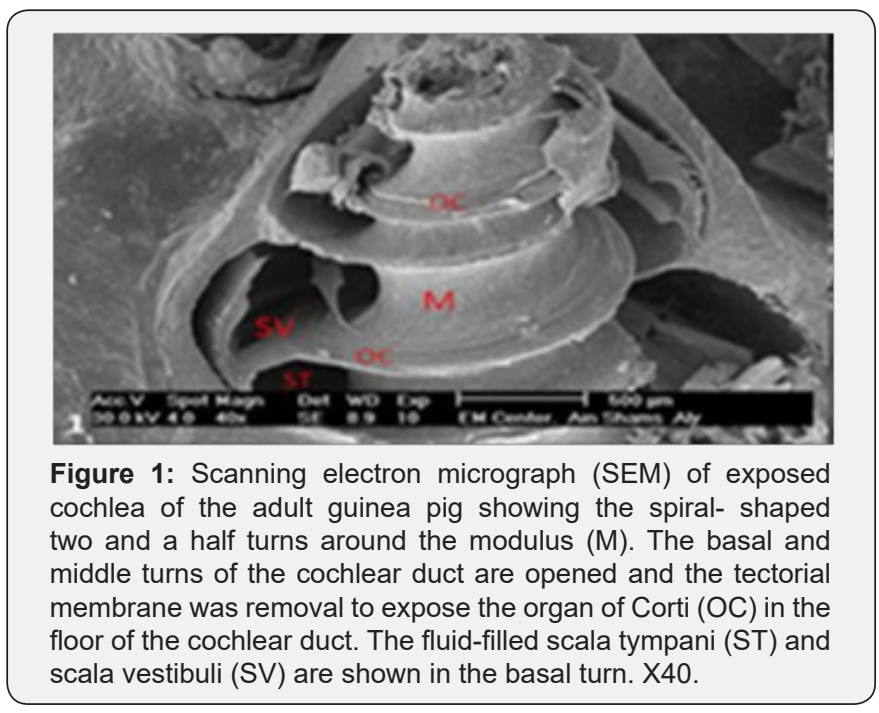




\section{Global Journal of Otolaryngology}

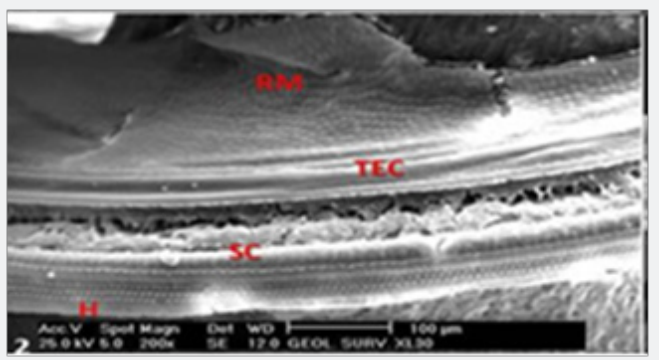

Figure 2: SEM of opened basal turn of the cochlear duct of control group, showing the three rows of outer hair cells, a raw of inner hair cells $(\mathrm{H})$, and the inner sulcus cells $(\mathrm{SC})$. The roof of the cochlear duct is the Reissner's membrane (RM). Note the squamous epithelial lining and the tectorial Membrane (TEC). X200.

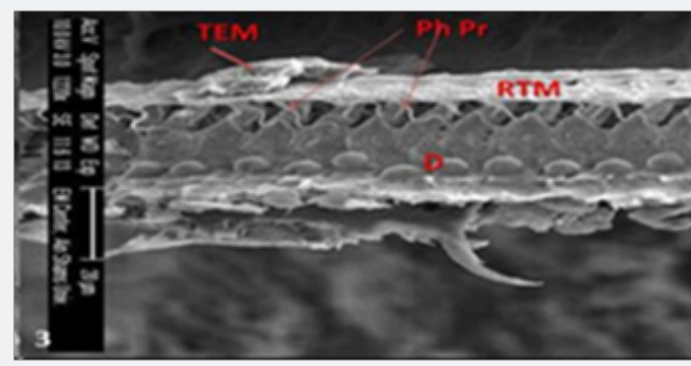

Figure 3: SEM of opened basal turn of the cochlear duct of control group, showing portion of the spiral organ of Corti dissected to expose the outer raw of hair cells. Note the outer hair.

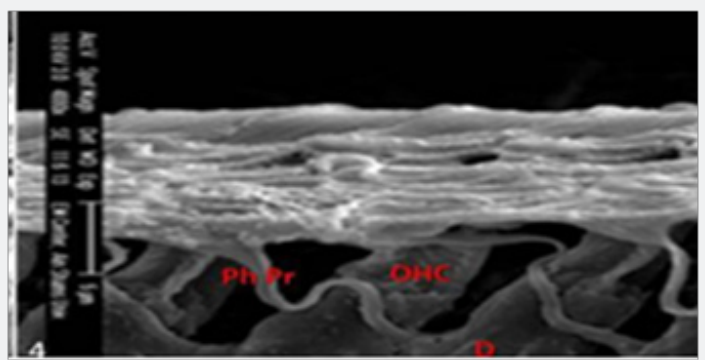

Figure 4: SEM of opened basal turn of the cochlear duct of control group at higher magnification showing the narrow phalangeal process $(\mathrm{PhPr})$ of Deiters cells $(\mathrm{D})$ that end in web like expansion extending between the hair cells to the reticular membrane. Note also that Deiters cell processes $(\mathrm{PhPr})$ cross at least one raw of outer hair cells (OHC). X 4880 .

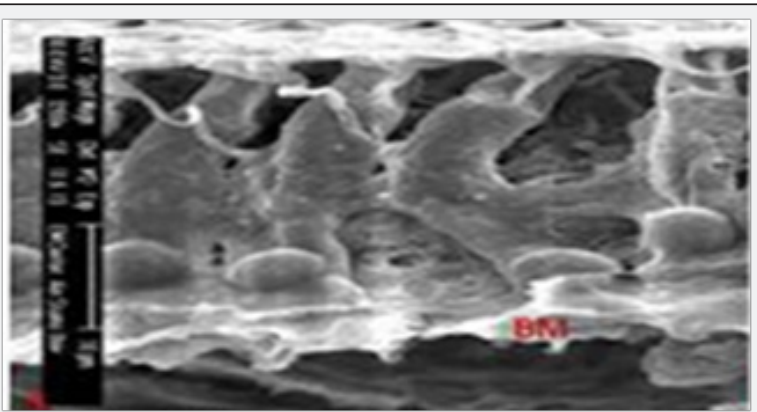

Figure 5: SEM of opened basal turn of the cochlear duct of control group at higher magnification, showing the rounded basal nuclei of Deiters cells and remnant of basilar membrane (BM). X 3200.

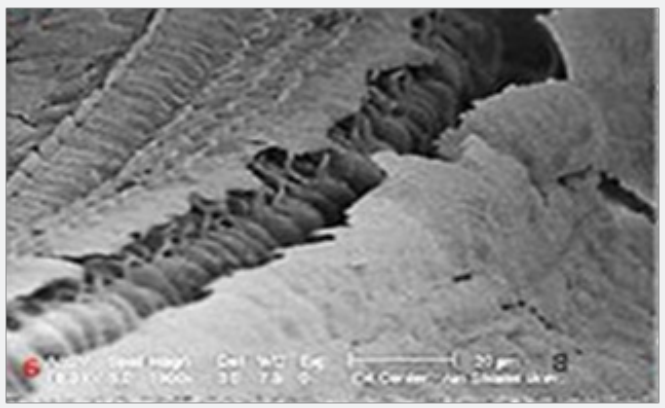

Figure 6: SEM of opened basal turn of the cochlear duct of control group showing the fractured reticular membrane exposing the organ of Corti and Deiters cells. X 1000.

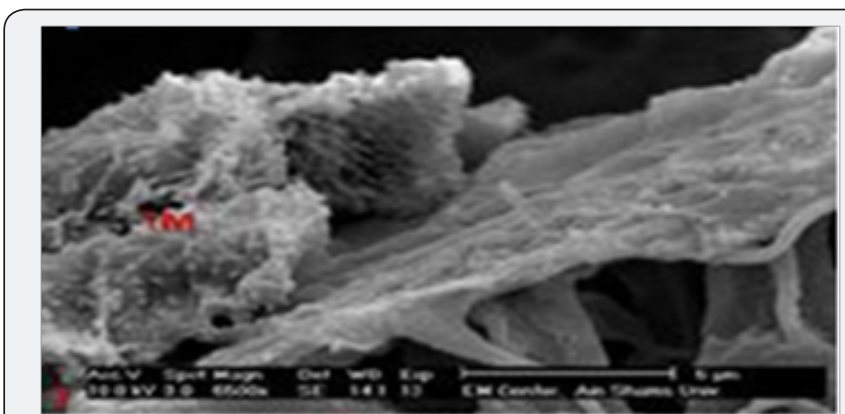

Figure 7: SEM of opened basal turn of the cochlear duct of control group at a higher magnification showing stiff, immobile keratinous-like structure of tectorial membrane (TM) where the sensory hair cells are inserted. X 6500.

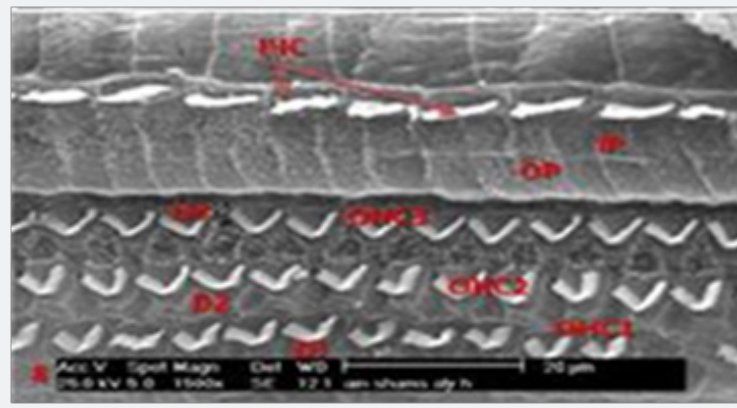

Figure 8: SEM of opened basal turn of the cochlear duct of control group at higher magnification showing outer hair cells formed of three rows $(\mathrm{OHC} 1,2,3)$ and inner hair cells $(\mathrm{IHC})$ formed of one row. Between them appear the outer pillar (OP) and the inner pillar (IP) cells. Deiters cells $(D 1,2,3)$ appear between the rows of the OHCs. X 1500.

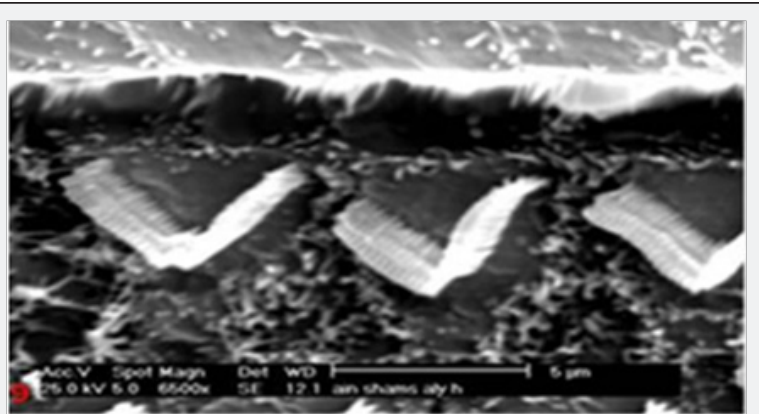

Figure 9: SEM of opened basal turn of the cochlear duct of control group at higher magnification showing outer hair cells carrying apical stereocilia in stair-case arrangement forming the characteristic typical V-shaped pattern ciliary bundles. X 6500 


\section{Global Journal of Otolaryngology}

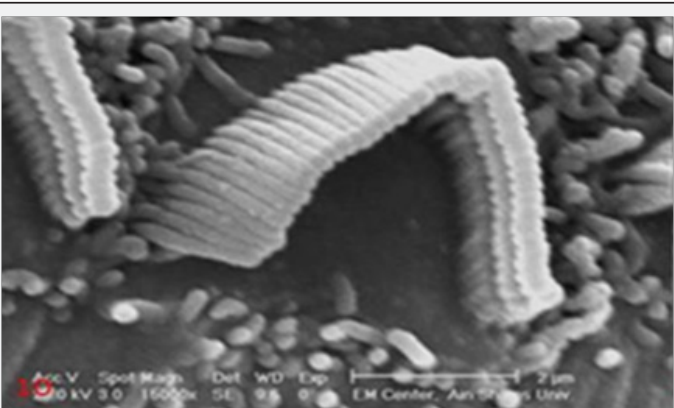

Figure 10: SEM of opened basal turn of the cochlear duct of control group showing that the stereocilia of outer hair cells within a single row are of the same height, whereas stereocilia of different rows are graded in height, the outermost row being the tallest. X 15000.

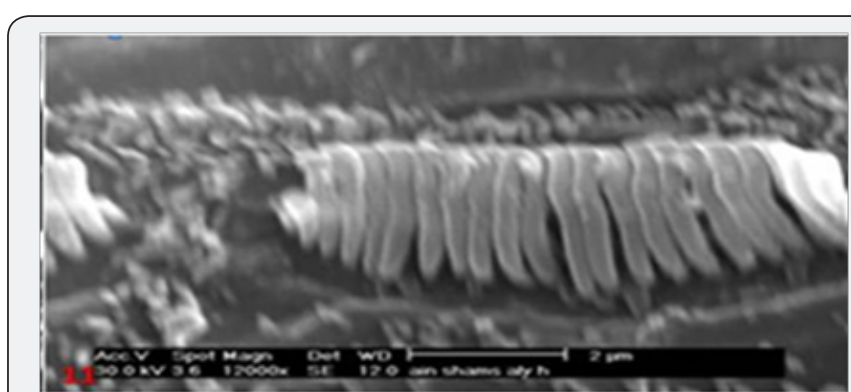

Figure 11: SEM of opened basal turn of the cochlear duct of control group showing that the stereocilia of the inner cells are arranged in a flattened U-shaped pattern and the ciliary bundles are free standing. X 12000.

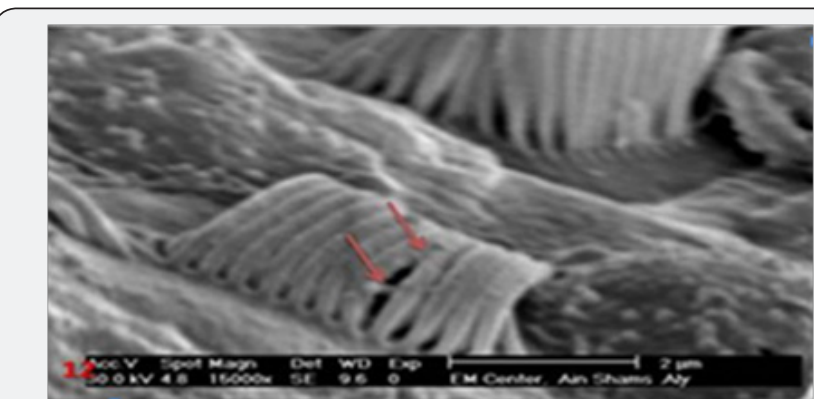

Figure 12: SEM of opened basal turn of the cochlear duct of control group showing filamentous structures forming cross-links (arrows) between stereocilia of the same row (side-to-side links) of inner hair cells. X 15000.

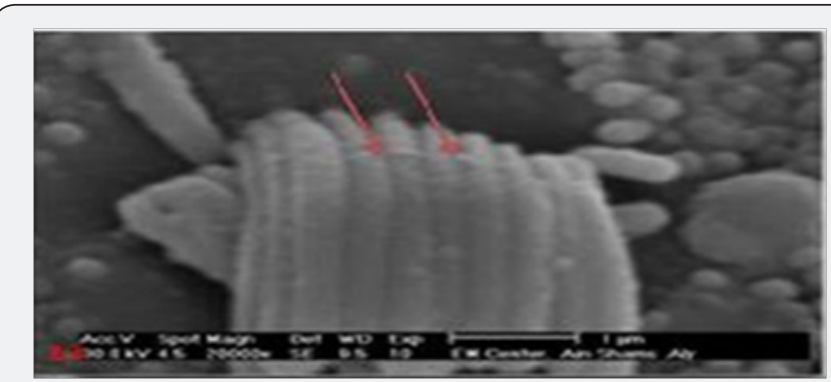

Figure 13: SEM of opened basal turn of the cochlear duct of control group showing filamentous structures forming cross-links (arrows) between stereocilia of the same row (side-to-side links) of outer hair cells that were numerous than that were seen in inner hair cells. X 20000.

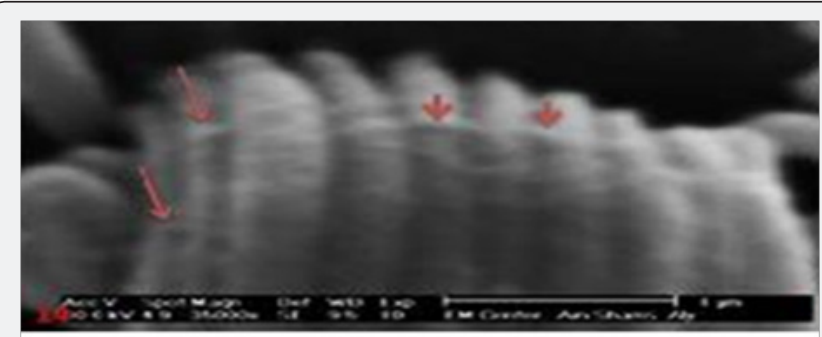

Figure 14: SEM of opened basal turn of the cochlear duct of control group at higher magnification showing that the linkage system of stereocilia include both transverse linkage of the same row (arrow heads) as well as oblique linkage between the three (the tallest and the middle and shortest rows stereocilia) of the outer hair cells (arrows). X 35000.

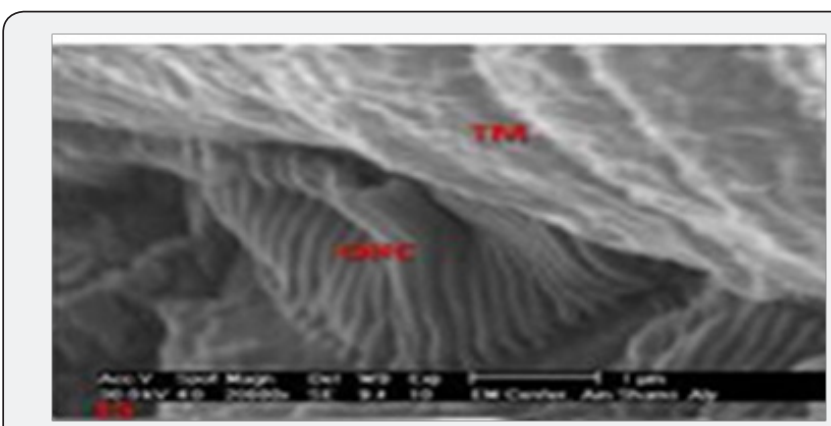

Figure 15: SEM of opened basal turn of the cochlear duct of control group showing that the OHCs are in close contact with the tectorial membrane (TM). X 20000.

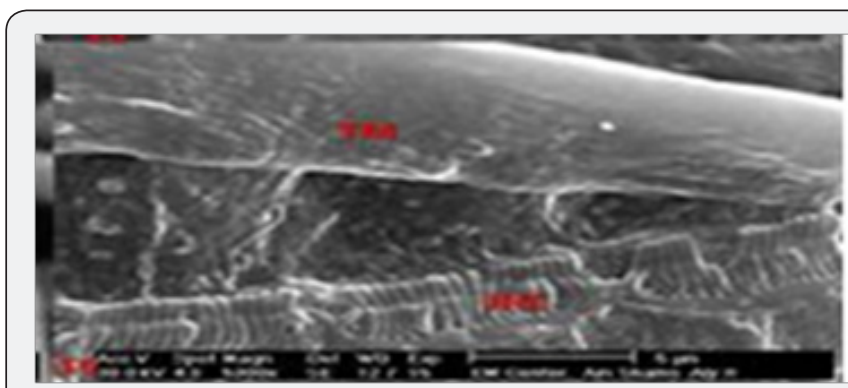

Figure 16: SEM of opened basal turn of the cochlear duct of control group showing that the IHCs are not reaching the tectorial membrane (TM). Note the thin basal portion of the stereocilia. $X$ 5000 .

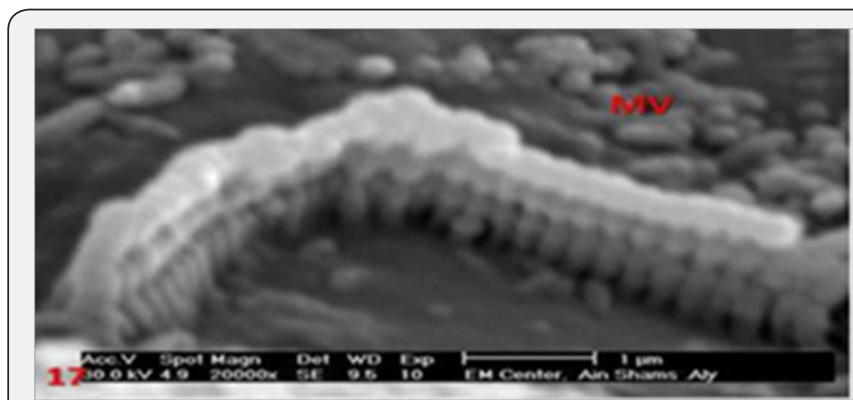

Figure 17: SEM of opened basal turn of the cochlear duct of control group showing the apex of one outer hair cell with different lengths of the stereocilia in the three rows. Note the characteristic microvilli (MV) of the apical portion of Deiters cells. X 20000. 


\section{Global Journal of Otolaryngology}

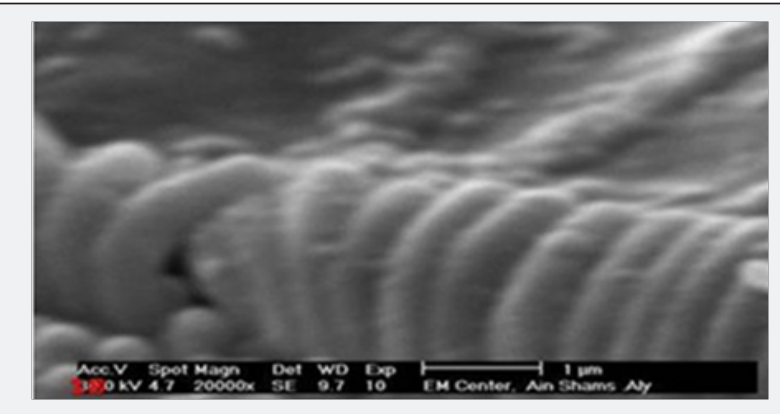

Figure 18: SEM of opened basal turn of the cochlear duct of control group showing that the IHCs stereocilia are of the same height. X 20000.

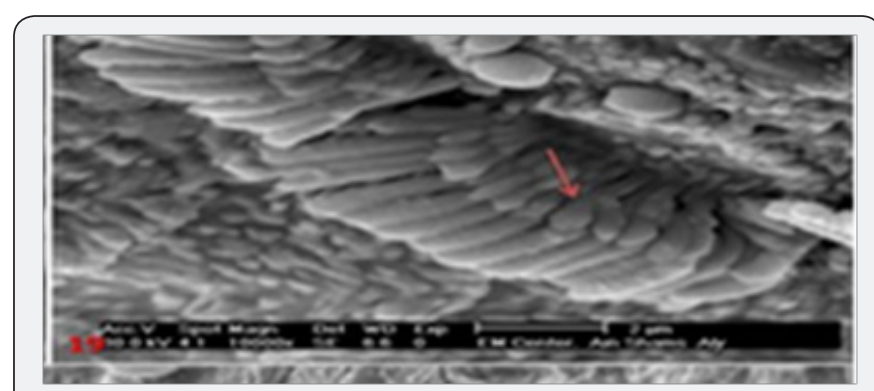

Figure 19: SEM of opened basal turn of the cochlear duct of control group showing that the stereocilia of the inner cells are arranged in a flattened U-shaped pattern. Note additional smaller and shorter inner row (arrow). X 10000.

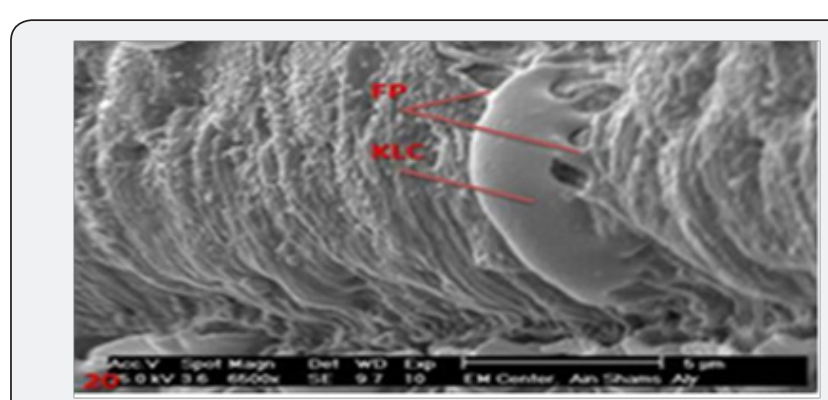

Figure 20: SEM of opened basal turn of the cochlear duct of control group showing a characteristic microphages (Kolmer like cell) (KLC), similar to epiplexus (Kolmer) cells of the ependyma, displaying diverse morphological forms bear a variable number of cellular process (foot process) (FP). The cells were seen close to the OHCs. Such association may play a role in the initiation and/or maintenance of the cellular immune response. X 6500 .

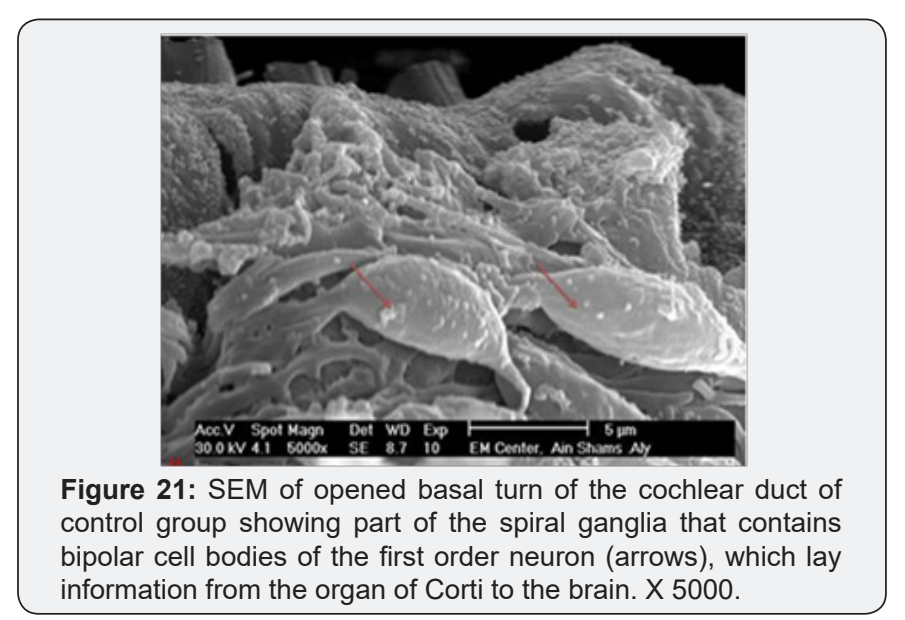

\section{SEM of Organ of Corti in The Experimental Groups}

a) Streptomycin treated animals showed almost complete absence of OHCs in the basal turn of the cochlea. The destruction of OHCs was evident as numerous irregular degraded remnant surface scar tissues. The apical fragment was retained in the reticular lamina and became surrounded basally by the expanded supporting cells (Figure 22). OHCs of the second turn presented an abnormal shortening of the stereocilia within a tuft, loss or partial degeneration and fusion with disorganized pattern (Figure 23). IHCs showed loss and severe degeneration (Figure 24), reminiscent of the specific atrophy of the ciliary tufts. First raw of OHCS of outer hair cells was severely affected (Figure 25). Occasionally slight swelling of spiral ganglion cells was observed in the streptomycin treated group (Figure 26).

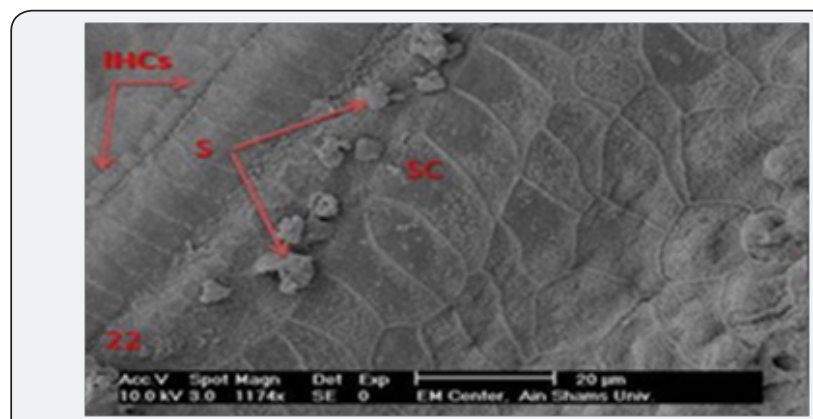

Figure 22: SEM of streptomycin induced cochlear injury. Note the destruction of outer hair cells that was evident as numerous irregular degraded remnant surface scar tissues (S). The apical fragment was retained in the reticular lamina and became surrounded basally by the expanded supporting cells (SC). Note also the nearly intact IHCs. X 1174.

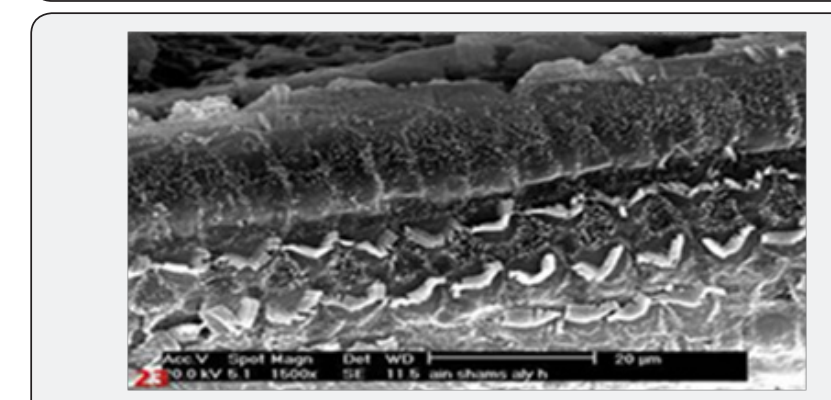

Figure 23: SEM of streptomycin induced cochlear injury showing the outer hair cells of the second turn with abnormal shortening of stereocilia, loss or partial degeneration and fusion with disorganized pattern. X 1500.

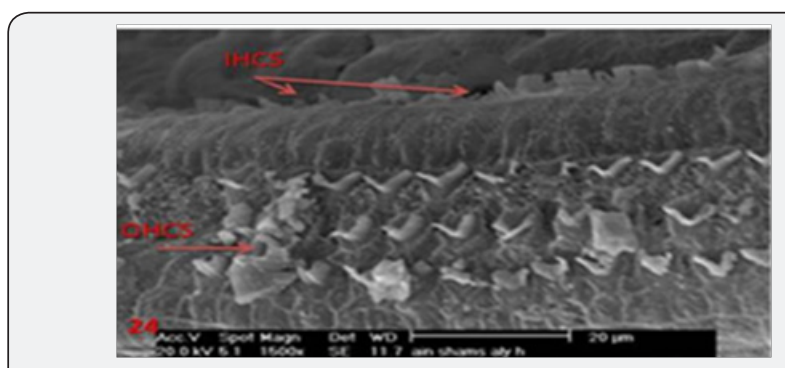

Figure 24: SEM of streptomycin induced cochlear injury showing loss and severe degeneration of the inner hair cells (IHCs). Note also that first and second outer hair cell rows (OHCs) were the most affected. X 1500 . 


\section{Global Journal of Otolaryngology}

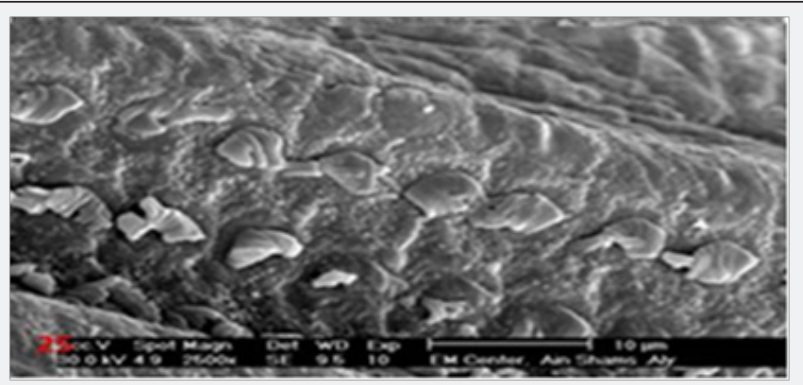

Figure 25: SEM of streptomycin induced cochlear injury showing severely affected first raw of outer hair cells. X 2500 .

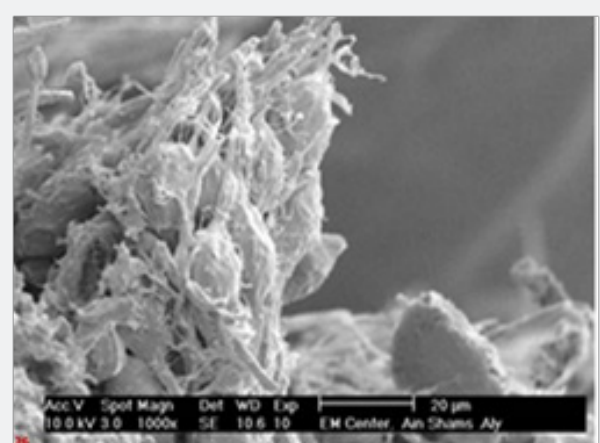

Figure 26: SEM of streptomycin induced cochlear injury showing slight swelling of Spiral ganglion cells. X 1000.

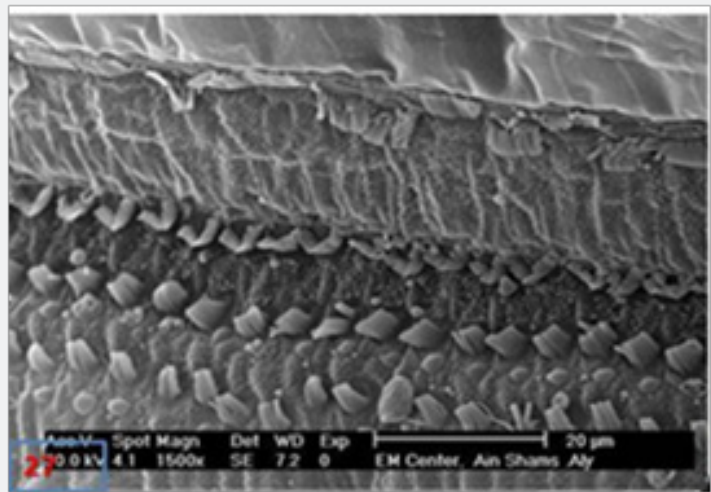

Figure 27: SEM of gentamycin induced cochlear injury showing mild disorganized IHCs with partial loss of stereocilia in first and second rows of OHCs. Note the apical blebbling of OHCs. X 1500.

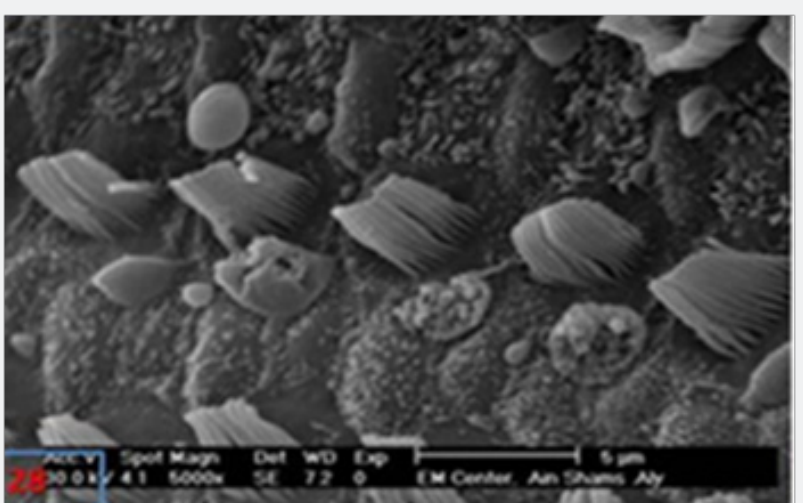

Figure 28: SEM of gentamycin induced cochlear injury at higher magnification showing partial and the complete ruptured apical blebs. Note slight edema of the supporting cells. X 5000 . b) Gentamycin group showed mild disorganized IHCs with partial loss of stereocilia in first and second rows of OHC with some apical blebbling of OHCs (Figure 27). Some of the blebs are showing partial or complete rupturing with slight oedema of the supporting cells (Figure 28).Intact apical blebs have a narrow stalk at posterolateral aspect of OHCs (Figure 29). However, spiral ganglion cells remained intact in all animals examined (Figure 30).

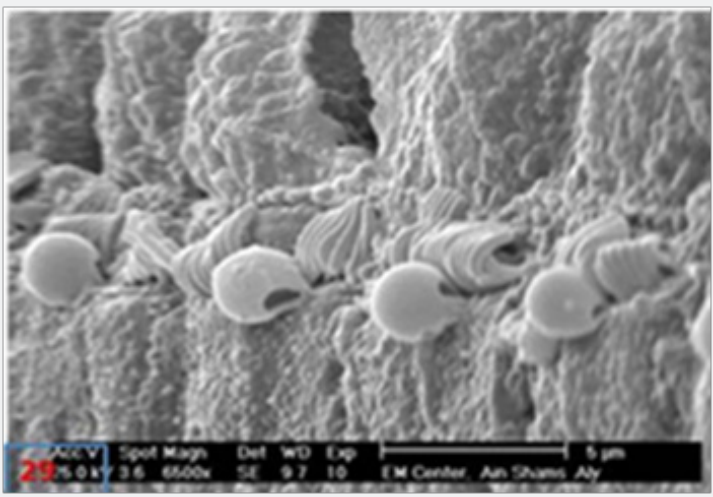

Figure 29: SEM of gentamycin induced cochlear injury at higher magnification showing the intact apical blebs that has narrow stalk at postero lateral aspect of outer hair cells. X 6500 .

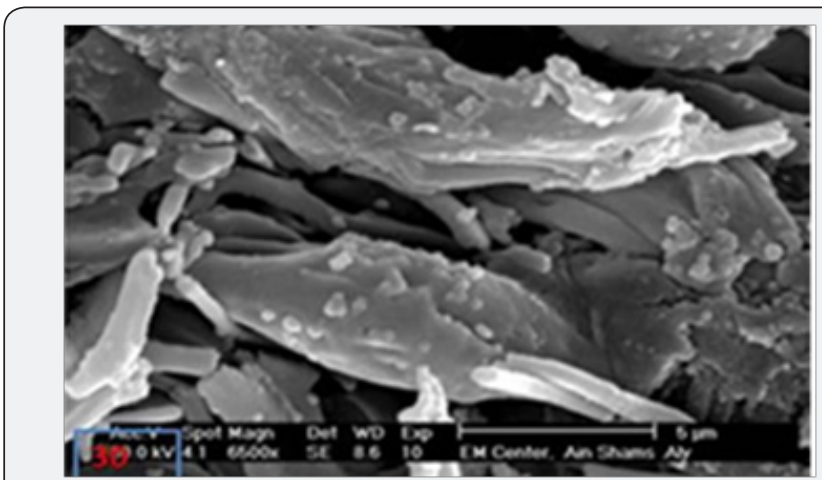

Figure 30: SEM of gentamycin induced cochlear injury showing that spiral ganglion cells remained intact in all animals examined. $\times 6500$.

c) Netilmicin induced very mild stereocilia loss of IHCs cells (Figure 31) and nearly intact OHCs (Figure 32). Slight oedematous observable swelling of the stereocilia of IHCs was noticed, with intact cross linkage giving it a knuckled appearance (Figure 33).

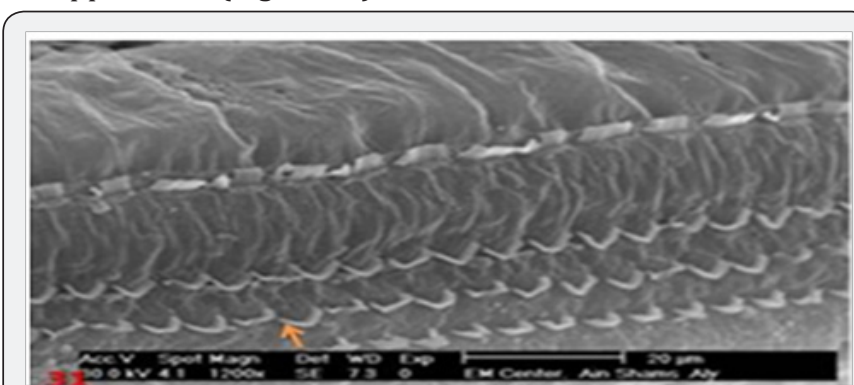

Figure 31: SEM of netilmicin induced cochlear injury showing very mild stereocilia loss of IHCs and nearly intact OHCs (arrow). $\mathrm{X} 1200$. 


\section{Global Journal of Otolaryngology}

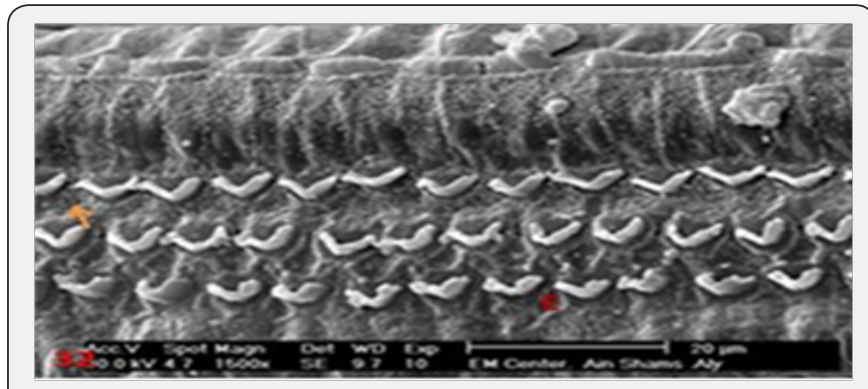

Figure 32: SEM of netilmicin induced cochlear injury showing very mild stereocilia loss of $\mathrm{IHCs}$ and nearly intact $\mathrm{OHCs}$ (arrow). Deiters cells (E) appear nearly intact between the rows of the OHCs X 1500.

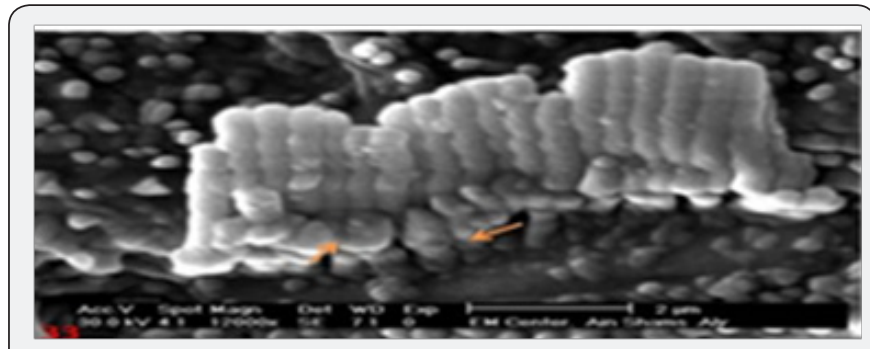

Figure 33: SEM of netilmicin induced cochlear injury showing slight edematous swelling of the stereocilia of IHCs; note the intact cross linkage giving it knuckled appearance (arrows). X12000.

\section{Semi-Quantitative Evaluation}

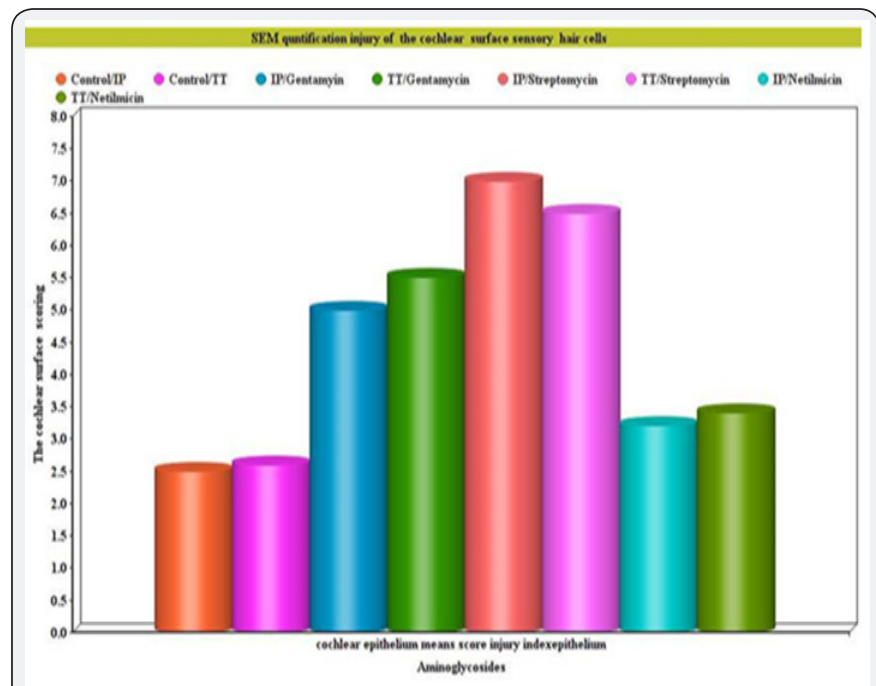

Graph 2: Mean of the sum of scanning observations scoring and standard deviation for cochlear sensory hair cell injury of guinea pig giving three different aminoglycosides.

The mean scoring of the SEM observations for sensory hair cell injury following the three aminoglycosides is represented in graph 2. Few morphological alteration was seen in the control groups (groups I and V). Generally the degenerative alteration due to systemic versus the trans-tympanic administration of the three aminoglycosides were similar at $\mathrm{p}>0.05$. The graph shows also that the most damaging effect on the cochlea was produced by streptomycin followed by gentamycin and netilmicin (Graph 2).

\section{Discussion}

Various studies could be found dealing with the morphology of the stereocilia of the hair cells following aminoglycosides toxicity [19-24]. However, there was no detailed description of the stereocilia of the normal hair cells. One of the most important results of the present work is providing unique information regarding the ultrastructure of the stereocilia of the hair cells and their cross-linking extracellular filaments that have been suggested to play a role in mechano-electrical transduction. Linkage system of stereocilia includes both transverse linkage of stereocilia of the same row of OHCs as well as oblique linkage between the three rows. Side -to-side links of OHCs were numerous than that seen in IHCs. The results obtained in this study indicated that aminoglycosides have deleterious effect on the cochlear tissue inducing hearing loss. However, the severity of the toxic effect differs from one drug to the other. The most severe changes were seen in animals given streptomycin followed, in order, by gentamycin and netilmicin. Such problems are significant as the drugs are still widely used to treat serious gram-negative infections. Moreover, up to $25 \%$ of patients treated with aminoglycosides develop irreversible neural hearing loss [25]. As mammalian hair cells do not regenerate, damage or loss of hair cells leads to permanent hearing impairment [26]. The results of the present work showed that the most severe effects were seen with streptomycin injection, either intraperitoneal or intratympanic. This was documented with the higher ABR thresholds, particularly at stimuli of 2, 8, 16, and $32 \mathrm{kHz}$, reaching up to $85 \mathrm{~dB}$, whereas it was $45 \mathrm{~dB}$ for the control group which received injections of normal saline. These results were further supported by the morphological SEM findings that OHCs and IHCs were severely damaged in guinea pigs receiving streptomycin. The damage was more in the basal turns of the cochlea than both middle and apical ones. First rows and the second of OHCs were more severely damaged than the third row. The destruction of OHCs was associated with replacement by supporting cells. Similar results were reported by other authors $[19,20]$. It was found that hair cells incubated in Hank's solution containing $1 \mathrm{mmol} / \mathrm{L}$ dihydrostreptomycin, initially deteriorated in 0.5-4.5 hours and progressed to entire degeneration after 10-20 hours [19]. It was also reported that significant increase in the threshold of ABR and damage of IHC and $\mathrm{OHC}$, spiral ganglion (SG) of the cochlea of guinea pig detected by light microscope, TEM and immunohistochemical staining [20]. The present study showed that administration of gentamycin led to formation of cytoplasmic apical blebs from the plasma membrane of the posterolateral aspect of the OHCs, followed by their rupture. The destruction of OHCs was associated with replacement by supporting cells. This is similar to the results described by other authors [22]. Our results showed also that gentamycin is middle in its cochlear toxicity. Similar result was seen by other authors where average threshold value of ABR was significantly higher in the gentamicin group as compared with that of the control group [23]. The 


\section{Global Journal of Otolaryngology}

animal model established by Okuda et al [24] showed that moderate damage of inner ear occur with moderate-dose of gentamycin. The effect of intraperitoneal gentamicin ototoxicity on the cochlea of the rats was studied with auditory brain stem responses (ABRs), and histopathological investigation [21]. ABR thresholds were attenuated and apoptosis was detected with histopathological investigation. Other studies showed that the effect of gentamycin is the most severe effect, compared to other aminoglycosides. In mixed-breed cats study, the severity of the cochlear damage was in the order gentamicin, amikacin, streptomycin, netilmicin, with gentamicin being the most toxic [27]. Using both SEM and TEM the ototoxicity of the aminoglycosides was ranked in the following order: neomycin> gentamicin $>$ dihydrostreptomycin $>$ amikacin $>$ neamine> spectinomycin [28]. Other study reported widespread ipsilateral cochlear neuroepithelial injuries with loss of otoacoustic emissions (OAEs), auditory brainstem evoked response (ABRs), and ice-water caloric response in the chinchilla model [29]. The study proves that the morphological damage following ototoxicity of gentamicin or streptomycin correlates with, but precedes loss of electrophysiological parameters. The present investigation suggests that netilmicin ototoxicity observed in both systemic and a transtympanic route is low. This may be attributed to lesser penetration into the inner ear and/or lower intrinsic toxicity. This was, further, confirmed by $\quad$ A $\quad$ B $\quad R$ thresholds of all aminoglycosides tested. A study using the 16th gestational day inner ear explants from fetal mice in organ culture system found that the less ototoxic potential of netilmicin as compared with other aminoglycosides is probably due to the drug itself and not primarily due to a poor penetration of netilmicin into the inner ear [30]. Sparing of the spiral ganglia was seen in most cases examined. Few spiral ganglia showed some degeneration of bipolar cells, while others showed edematous swelling. Despite the absence of hair cells, ganglion cells were, however, able to survive for considerable periods of time. Similar observation was documented by other authors $[20,31]$. It was suggested that in cases of aminoglycoside ototoxicity in human, spiral ganglion cell reduction may be present in segments of the cochlea with normal-appearing [32]. It is also suggested that aminoglycoside can injure spiral ganglion cells directly, as well as hair cells. Some authors [33, 34] studied the nerve endings on the lower poles of the outer hair cells of the organ of Corti of the guinea pig. Although they described clear evidence of ultra structural change in the cilia of the hair cells after administration of ototoxic drugs, there was no evidence of concomitant ultrastructural change in the nerve endings. They concluded that nerve endings appeared to be more resistant than the hair cells. Prior studies have shown that the avian inner ear contains resident populations of macrophages and that hair cell injury leads to macrophage activation and recruitment [3538]. Resident macrophages have been described in the human middle ear mucosa [39], below the dark cell area of the vestibular system [40], and in the endolymphatic sac [41-43]. However, the remainder of the labyrinth, including the cochlea was once thought of as immuno-privileged. In 1990, data in guinea pigs demonstrated dendritic macrophages phagocytizing degenerating cells and debris in the tunnel of Corti and outer hair cell region but authors mentioned that these cells may be derived from blood-borne monocytes [44]. All reports failed to demonstrate the presence of surface scavenger microphages in close association with auditory hair cells; rather they confirmed their subepithelial stromal tissue that underlies the sensory epithelium residency after blood recruitment. Such findings indicate that the loss of hair cells leads to the recruitment of macrophages into the sensory epithelium. In the present work characteristic large cell population of microphages-like cells similar to epiplexus (Kolmer) cells of brain choroid plexus were seen in close association with normal auditory OHCs surface. They bear a variable number of cellular processes (foot process). Moreover, the insertion of cell filiopodia into the reticular membrane was noticed. Such immune cells are residing even under physiological conditions. These cells may be part of the immune surveillance of organ of Corti. They may be capable of movement or migration to injured areas and may play a role in the initiation and/or maintenance of the cellular immune response. Much has been performed to investigate the causes and mechanisms of ototoxicity, to try to prevent this complication. Despite researchers' efforts, ototoxicity still occurs, and there is much work to be done in order to understand the mechanism of ototoxicity of different drugs and to prevent hearing loss in the future. There were few trials to describe the role of certain factors in the production of the cochlear toxicity. Aminoglycosides are endocytosed at the apical membranes of hair cells, i.e., from endolymph, and transported to lysosomes [16]. Previous studies have demonstrated that the level of aminoglycoside in the inner ear endolymph does not reach that of plasma, but its clearance time is extremely slow $>30$ days [45]. At present, the basis for the different effects of each drug is unknown. The mechanisms of cochleotoxicity are deemed worthy of further study. Increasing our understanding of aminoglycosides induced ototoxicity requires greater insight into the mechanisms of cellular uptake kinetics, trans-cellular trafficking and intracellular disruption of physiological activities by aminoglycosides, modifying dosing protocols, the structure of current aminoglycosides, and/or increased verification of candidate oto-protective agents could all enable aminoglycosides to be used more readily with reduced risks of lifelong ototoxicity in hospital.

\section{Conclusion}

The present study provides unique comprehensive description of the SEM morphology of the control and aminoglycosides treated cochlear tissue. The stereociliary hair cells of the control group were found to contain cross-linking extracellular filaments that could play a role in mechanoelectrical transduction. The study strongly supports previous studies for the toxic effect of the three most commonly used aminoglycosides; streptomycin, gentamycin, and netilmicin on the cochlear system. The most severe changes were seen after 
streptomycin followed, in order, by gentamycin and netilmicin. Streptomycin caused destruction of OHCs associated with replacement by supporting cells. Gentamycin caused cytoplasmic blebs formation of the plasma membrane of the sensory hair cells followed by their rupture. This study indicates that netilmicin is potentially safe for administration. Moreover, we demonstrated the presence of surface scavenger microphages in close association with the auditory hair cells under physiological conditions. Such cell may be of a part of the resident immune surveillance of organ of Corti.

\section{References}

1. Nobili R, Mammano F, Ashmore J (1998) How well do we understand the cochlea? Trends Neurosci 21(4): 159-167.

2. Wan G, Corfas G, Stone JS (2013) Inner ear supporting cells: rethinking the silent majority. Semin Cell Dev Biol 24(5): 448-459.

3. Zheng F, Zuo J (2017) Cochlear hair cell regeneration after noiseinduced hearing loss: Does regeneration follow development? Hear Res 349: 182-196.

4. Barclay ML, Begg EJ (1994) Aminoglycoside toxicity and relation to dose regimen. Adverse Drug React Toxicol Rev 13(4): 207-234.

5. Brummett RE (1980) Drug induced ototoxicity. Drugs 19(6): 412-428.

6. Lerner SA, Matz GJ (1980) Aminoglycoside ototoxicity. American journal of otolaryngology 1(2): 169-179.

7. Kahlmeter G, Dahlager JI (1984) Aminoglycoside toxicity-A review of clinical studies published between 1975 and 1982. The Journal of antimicrobial chemotherapy 13 Suppl A: 9-22.

8. Cone LA (1982) A survey of prospective, controlled clinical trials of gentamicin, tobramycin, amikacin, and netilmicin. Clin Ther 5(2): 155162

9. PJ Govaerts, J Claes, PH Van De Heyning, Ph G Jorens, J Marquet, et al. (1990) Aminoglycoside induced ototoxicity. Toxicology letters 52(3): 227-251.

10. Moore RD, Smith CR, Lietman PS (1984) Risk factors for the development of auditory toxicity in patients receiving aminoglycosides. J Infect Dis 149(1): 23-30.

11. Alharazneh A, Luk L, Huth M, Monfared A, Steyger PS, et al. (2011) Functional hair cell mechanotransducer channels are required for aminoglycoside ototoxicity. PloS one 6(7): e22347.

12. Ja Won Koo, Lourdes Quintanilla Dieck, Meiyan Jiang, Jianping Liu, Zachary D Urdang, et al. (2015) Endotoxemia mediated inflammation potentiates aminoglycoside induced ototoxicity. Science translational medicine 7(298): 298ra118.

13. Jiang M, Karasawa T, Steyger PS (2017) Aminoglycoside Induced Cochleotoxicity: A Review. Front Cell Neurosci 11: 308

14. Yves Brand, Cristian Setz, Soledad Levano, Alwin Listyo, Eduardo Chavez, et al. (2011) Simvastatin protects auditory hair cells from gentamicin induced toxicity and activates Akt signaling in vitro. BMC neuroscience 12: 114 .

15. Choung YH, Taura A, Pak K, Choi SJ, Masuda M, et al. (2009) Generation of highly reactive oxygen species is closely related to hair cell damage in rat organ of Corti treated with gentamicin. Neuroscience 161(1): 214-226.

16. Hailey DW, Esterberg R, Linbo TH, Rubel EW, Raible DW (2017) Fluorescent aminoglycosides reveal intracellular trafficking routes in mechanosensory hair cells. J Clin Invest 127(2): 472-486.
17. Jadali A, Kwan KY (2016) Activation of PI3K signaling prevents aminoglycoside induced hair cell death in the murine cochlea. Biol Open 5(6): 698-708.

18. Murillo Cuesta S, Vallecillo N, Cediel R, Celaya AM, Lassaletta L, et al (2017) A Comparative Study of Drug Delivery Methods Targeted to the Mouse Inner Ear: Bullostomy Versus Transtympanic Injection. J Vis $\operatorname{Exp}(121)$.

19. Su Z, Sun Y, Jiang S (1996) [The cochlea in short-term culture]. Zhonghua er bi yan hou ke za zhi 31(3): 133-135.

20. Shi LJ, Tang H (2005) [Effect of injection salvia miltiorrhiza on the expression of inducible nitric oxide synthase in the cochlea of guinea pig damaged by streptomycin]. Zhongguo ying yong sheng li xue za zhi, Zhongguo yingyong shenglixue zazhi, Chinese journal of applied physiology 21(1): 96-99.

21. Somdas MA, Korkmaz F, Gurgen SG, Sagit M, Akcadag A (2015) $\mathrm{N}$-acetylcysteine Prevents Gentamicin Ototoxicity in a Rat Model. J Int Adv Otol 11(1): 12-18.

22. Forge A (1985) Outer hair cell loss and supporting cell expansion following chronic gentamicin treatment. Hear Res 19(2): 171-182.

23. Zhou P, Ma W, Sheng Y, Duan M, Zhang X (2017) Protective Effects of Acupuncture Against Gentamicin-Induced Ototoxicity in Rats: Possible Role of Neurotrophin-3. Medical science monitor: Med Sci Monit 23: 446-451.

24. Okuda T, Sugahara K, Shimogori H, Yamashita H (2004) Inner ear changes with intracochlear gentamicin administration in Guinea pigs. Laryngoscope 114(4): 694-697.

25. Rybak LP, Ramkumar V (2007) Ototoxicity. Kidney Int 72(8): 931-935.

26. Cheng AG, Cunningham LL, Rubel EW (2003) Hair cell death in the avian basilar papilla: characterization of the in vitro model and caspase activation. Journal of the Association for Research in Otolaryngology : JARO 4(1): 91-105.

27. Kalkandelen S, Selimoğlu E, Erdoğan F, Uçüncü H, Altaş E (2002) Comparative cochlear toxicities of streptomycin, gentamicin, amikacin and netilmicin in guinea-pigs. J Int Med Res 30(4): 406-412.

28. Kotecha B, Richardson GP (1994) Ototoxicity in vitro: effects of neomycin, gentamicin, dihydrostreptomycin, amikacin, spectinomycin, neamine, spermine and poly-L-lysine. Hearing research 73(2): 173184.

29. Hilton M, Chen J, Kakigi A, Hirakawa H, Mount RJ, et al. (2002) Middle ear instillation of gentamicin and streptomycin in chinchillas: electrophysiological appraisal of selective ototoxicity. Clin Otolaryngol Allied Sci 27(6): 529-535.

30. Anniko M (1983) Aspects on the ototoxic potential of netilmicin. Acta oto-laryngologica 96(1-2): 75-89.

31. Dodson HC, Mohuiddin A (2000) Response of spiral ganglion neurones to cochlear hair cell destruction in the guinea pig. Journal of neurocytology 29(7): 525-537.

32. Hinojosa R, Nelson EG, Lerner SA, Red leaf MI, Schramm DR (2001) Aminoglycoside ototoxicity: a human temporal bone study. Laryngoscope 111(10): 1797-1805.

33. Harada Y, Hirakawa K, Mangape D (1983) Scanning electron microscopy of the nerve endings of Corti's organ. Scan Electron Microsc (Pt 1): 183-188.

34. Harada Y, Mangape D, Tagashira N (1985) A study of the nerve endings of the outer hair cells in the organ of Corti--using scanning electron microscopy. Auris Nasus Larynx 12(1): 5-14.

35. Stefater JA, Ren S, Lang RA, Duffield JS (2011) Metchnikoff's policemen: macrophages in development, homeostasis and regeneration. Trends Mol Med 17(12): 743-752. 


\section{Global Journal of Otolaryngology}

36. Hirose K, Discolo CM, Keasler JR, Ransohoff R (2005) Mononuclear phagocytes migrate into the murine cochlea after acoustic trauma. J Comp Neurol 489(2): 180-194.

37. Warchol ME, Schwendener RA, Hirose K (2012) Depletion of resident macrophages does not alter sensory regeneration in the avian cochlea. PloS one 7(12): e51574.

38. 0 Malley JT, Nadol JB, J McKenna MJ (2016) Anti CD163+, Iba1+, and $\mathrm{CD} 8^{+}$Cells in the Adult Human Inner Ear: Normal Distribution of an Unappreciated Class of Macrophages/Microglia and Implications for Inflammatory Otopathology in Humans. Otology \& neurotology: official publication of the American Otological Society, American Neurotology Society [and] European Academy of Otology and Neurotology 37(1): 99-108.

39. Lim DJ (1976) Functional morphology of the mucosa of the middle ear and Eustachian tube. Ann Otol Rhinol Laryngol 85(2 Suppl 25 Pt 2): 36-43.

40. Masuda M, Yamazaki K, Kanzaki J, Hosoda Y (1997) Immunohistochemical and ultrastructural investigation of the human vestibular dark cell area: roles of subepithelial capillaries and $\mathrm{T}$ lymphocyte-melanophage interaction in an immune surveillance system. The Anatomical record 249(2): 153-162.

41. Altermatt HJ, Gebbers JO, Müller C, Arnold W, Laissue JA (1990) Human endolymphatic sac: evidence for a role in inner ear immune defence. ORL J Otorhinolaryngol Relat Spec 52(3): 143-148.

42. Rask Andersen H, Danckwardt Lilliestrom N, Friberg U, House W (1991) Lymphocyte macrophage activity in the human endolymphatic sac. Acta oto laryngologica. Supplementum 485: 15-17.

43. Jansson B, Rask Andersen H (1992) Osmotically induced macrophage activity in the endolymphatic sac. On the possible interaction between periaqueductal bone marrow cells and the endolymphatic sac. ORL journal for oto rhino laryngology and its related specialties 54(4): 191-197.

44. Fredelius L, Rask Andersen H (1990) The role of macrophages in the disposal of degeneration products within the organ of corti after acoustic overstimulation. Acta oto laryngologica 109(1-2): 76-82.

45. Ricci AJ, Kachar B, Gale J, Van Netten SM (2006) Mechano electrical transduction: new insights into old ideas. J Membr Biol 209(2-3): 71 88.

\section{Your next submission with Juniper Publishers} will reach you the below assets

- Quality Editorial service

- Swift Peer Review

- Reprints availability

- E-prints Service

- Manuscript Podcast for convenient understanding

- Global attainment for your research

- Manuscript accessibility in different formats

( Pdf, E-pub, Full Text, Audio)

- Unceasing customer service

Track the below URL for one-step submission https://juniperpublishers.com/online-submission.php 